\title{
Does i-T744C P2Y12 Polymorphism Modulate Clopidogrel Response among Moroccan Acute Coronary Syndromes Patients?
}

\author{
Hind Hassani Idrissi, ${ }^{1}$ Wiam Hmimech, ${ }^{1}$ Nada El Khorb, ${ }^{2}$ Hafid Akoudad, \\ Rachida Habbal, ${ }^{3}$ and Sellama Nadifi ${ }^{1}$ \\ ${ }^{1}$ Laboratory of Genetics and Molecular Pathology, Medical School, University Hassan II, Casablanca, Morocco \\ ${ }^{2}$ Department of Cardiology, University Hospital Center Hassan II, Fes, Morocco \\ ${ }^{3}$ Department of Cardiology, University Hospital Center Ibn Rochd, Casablanca, Morocco
}

Correspondence should be addressed to Hind Hassani Idrissi; hassani-idrissi-hind@hotmail.fr

Received 17 October 2016; Revised 3 January 2017; Accepted 12 January 2017; Published 5 February 2017

Academic Editor: Norman A. Doggett

Copyright (C) 2017 Hind Hassani Idrissi et al. This is an open access article distributed under the Creative Commons Attribution License, which permits unrestricted use, distribution, and reproduction in any medium, provided the original work is properly cited.

\begin{abstract}
Background. An interindividual variability in response to Clopidogrel has been widely described in patients with acute coronary syndromes (ACS). The contribution of genetics on modulating this response was widely discussed. The objective of our study was to investigate the potential effect of i-T744C P2Y12 polymorphism on Clopidogrel response in a sample of Moroccan ACS patients. We tried also to determine the frequency of this polymorphism among Moroccan ACS compared to healthy subjects. Methods and Results. 77 ACS patients versus 101 healthy controls were recruited. DNA samples were genotyped by PCR-RFLP method. The VerifyNow assay was used to evaluate platelet function among ACS patients. Our results show that the mutant allele $\mathrm{C}$ was more frequent among ACS ST (+) than ST (-) patients (39\% versus 19.8\%, resp.), when the wild-type allele was more represented in the ACS ST (-) group (80.2\%). The C allele frequency was higher among resistant than nonresistant patients (30\% versus $20.8 \%$, resp.). Comparison of ACS patients and healthy controls shows higher frequency of mutant C allele among cases compared to controls (22.73\% versus $19.31 \%$, resp.); there was a statistically significant association of the recessive and additive transmission models with the ACS development risk (OR $[95 \% \mathrm{CI}]=1.78$ [1.58-5.05], $P=0.01$ and $\mathrm{OR}[95 \% \mathrm{CI}]=1.23[0.74-2.03], P<0.001$, resp.), increasing thus the association of this polymorphism with the pathology. Conclusion. Our results suggest that this polymorphism may have a potential effect on Clopidogrel response among our Moroccan ACS patients and also on ACS development.
\end{abstract}

\section{Background}

Because the majority of cardiovascular diseases are the result of an occlusive thrombosis, numerous antithrombotic drugs are used in there therapy, including platelet inhibitors and oral anticoagulants [1].

Clopidogrel is a thienopyridine derivative, used to inhibit the formation of blood clots in coronary artery disease, peripheral vascular disease, and stroke. It irreversibly inhibits the receptor of adenosine diphosphate (ADP), called P2Y12, expressed on the surface of platelets. This prodrug requires a hepatic oxidation step by the cytochrome P450 (CYP450) enzymes, to generate the active metabolite responsible for the irreversible blocking effect of the $\mathrm{P} 2 \mathrm{Y} 12$ receptor during the life of the platelet [2].
In Acute Coronary Syndrome (ACS), a wide range of interindividual variations in platelet response to Clopidogrel, has been described. An important proportion of patients still experience thrombotic events even after receiving the treatment, so they do not reach the same degree of benefit from the given drug [3]. Several factors were found to be in association with this heterogeneity in response to antithrombotic agents among patients $[4,5]$. The role of pharmacogenomics is to study the genetic factors that determine the response of a given individual to a given drug. This variability of response to treatment may explain both its efficacy and its adverse side effects [6].

Several genes are involved in the modulation of this response. These genes may act in absorption of the molecule: 
transportation (ABCB), metabolism (cytochromes), excretion (for side effects), or targets of direct or indirect action of the molecule (receptors: P2Y12, Gp IIb/IIIa, Gp Ia/IIa, etc.) [7-15].

P2Y12. The P2Y12 is the platelet receptor for adenosine diphosphate (ADP) targeted by the active form of Clopidogrel [16]. The protein encoded by this gene belongs to the big family of G-protein coupled receptors, which contains several receptor groups with different pharmacological selectivity. It is involved in platelet aggregation and is a potential target for the treatment of thromboembolic pathologies and clotting disorders. The P2Y12 gene is localized on human chromosome 3 (3q25.1); it covers $47.97 \mathrm{pb}$ of length. Mutations in this gene are implicated in bleeding disorder, platelet type 8 (BDPLT8). Many studies have assessed the functional role of the P2Y12 gene variants in modulating the response to antiplatelet drugs $[11,17]$. Recently, the T744C polymorphism of the P2Y12 receptor gene has been associated with enhanced platelet aggregation in healthy volunteers, suggesting a possible mechanism for modulation of Clopidogrel response $[18,19]$.

The main objectives of our study is to determine the frequency of i-T744C P2Y12 polymorphism among Moroccan ACS and healthy subjects and to assess whether or not the Clopidogrel response may be influenced by this genetic polymorphism in a sample of Moroccan ASC patients.

\section{Materials and Methods}

2.1. Study Population. Patients were eligible for inclusion if they had documented antiplatelet therapy (Clopidogrel), a VerifyNow P2Y12 platelet function test, and no more heparin in their blood. Patients were excluded if they did not have a VerifyNow P2Y12 platelet function test or having incomplete clinical data. All patients received a baseline P2Y12 platelet function test to identify Clopidogrel resistance and determine whether they would need another loading dose to achieve P2Y12 response (PRU PRU $<208$ and inhibition $\% \geq 20 \%$ ).

Blood samples were collected from 77 unrelated ACS Moroccan patients and 101 apparently healthy subjects showing no symptoms of coronary artery diseases. Clinical data concerning risk factors, biological parameters, and the VerifyNow test results were collected; an informed consent that was approved by the Ethical Committee of the University of Hassan II, School of Medecine, Casablanca, was signed by each patient and control before entering the study.

2.2. Study Protocol. Recruited patients received $300 \mathrm{mg}$ loading dose of the generic molecule; it was replaced by $75 \mathrm{mg}$ maintenance dose of Plavix for 7 days (washout period) if Clopidogrel resistance was noted on the initial platelet test (PRU > 208); a $300 \mathrm{mg}$ loading dose of Plavix was prescribed if the PRU remains and the resistance persists; inhibition was considered adequate for good response to treatment if the value reached $\geq 20 \%$.

The VerifyNow test (Accumetrics Inc., San Diego, California) was used to evaluate platelet function, as it is a point-ofcare assay, easy to perform, and rapid and uses small volumes of whole blood samples [20]. Two results are reported: the PRU (P2Y12 Reactive Units) and the percent inhibition. The ideal percent of platelet inhibition is $\geq 30 \%$ for Clopidogrel; however, $20-30 \%$ inhibition is considered as intermediate response [21, 22]. In our study, resistance to Clopidogrel was defined by $<20 \%$ inhibition + PRU $>208$ after many platelet function tests and nonresistance by $\geq 20 \%$ inhibition + PRU $<208$.

2.3. DNA Extraction. Venous blood from all participants in this study was collected in EDTA tubes. Samples were treated immediately or stored at $-20^{\circ} \mathrm{C}$ until extraction of DNA. Genomic DNA was extracted from blood leukocytes using the standard method of salting out [23].

2.4. Genotype Determination. We used PCR-RFLP to genotype samples for i-T744C P2Y12 polymorphism, as previously described by Malek et al. [16]. Genotyping of this variant was performed by amplification from 50 to $100 \mathrm{ng}$ of genomic DNA, followed by digestion using RsaI restriction enzyme. The digestion gave rise to three profiles: wild TT homozygous (one fragment of $220 \mathrm{pb}$ ), TC heterozygote (two fragments of 220 and $196 \mathrm{bp}$ ), and mutated CC homozygous (one fragment of $196 \mathrm{bp}$ ). The digested product was separated on 3\% agarose gel electrophoresis stained with Ethidium Bromide (BET) and visualized with UV rays.

2.5. Statistical Analysis. Statistical analysis was performed using SPSS 21.0 software. Chi square test $\left(\chi^{2}\right)$ was used to determine statistical significance of association/nonassociation between genotypes and classical risk factors. HardyWeinberg equilibrium (HWE) test was performed for cases and controls groups. Odds ratio (OR) were calculated to estimate the association between genotypes and ACS risk, using a Confidence Interval (CI) of 95\%. Significance was approved at $P$ value less than 0.05 .

\section{Results}

3.1. Characteristics of the Study Population. The distribution of i-T744C P2Y12 polymorphism was in Hardy-Weinberg equilibrium (HWE) for controls and cases groups (Table 1). The average age was $57.33 \pm 9.7$ for patients versus $32 \pm 9.87$ for healthy controls. There was a predominance of male in both groups (cases: 54.54\%; controls: 53.52\%) (Table 2). Table 3 describes the routine pathology data for our 77 SCA patients; $79.6 \%$ of these patients were under IPP, when $20.4 \%$ were not.

3.2. VerifyNow Results versus Risk Factors. Patients were placed into resistant and nonresistant groups, based on their platelet function test results, and the baseline characteristics of these patients correlated to resistance groups are shown in Table 4: only creatinine level, fibrinogen, $\mathrm{Pq}$ numerisation, and IPP use show statistically significant association $(P=$ $0.01 ; 0.04 ; 0.04$; and 0.03 , resp.).

3.3. Allelic Frequencies. When correlating i-T744C P2Y12 genotypes to the classical risk factors of the pathology, a statistically significant association was found with familial 
TABLE 1: HWE among cases and controls.

\begin{tabular}{lcccc}
\hline \multirow{2}{*}{ Genotypes } & \multicolumn{3}{c}{ EHW cases } & \multicolumn{2}{c}{ EHW controls } \\
& $\chi^{2}$ square & $P$ value $(P>0.05)$ & $\chi^{2}$ square & $P$ value $(P>0.05)$ \\
\hline i-T744C P2Y12 (rs2046934) & 1.35 & $\mathbf{0 . 5 1}^{*}$ & 4.26 & $\mathbf{0 . 1 3}^{*}$ \\
\hline${ }^{*}$ - & & &
\end{tabular}

* Statistically significant.

TABLE 2: Description of ACS study population.

\begin{tabular}{lcc}
\hline & ACS patients & Controls \\
\hline $\begin{array}{l}\text { Age (years) } \\
\text { Age of disease occurrence } \\
\text { (years) }\end{array}$ & $57.33 \pm 9.7$ & $32 \pm 9.87$ \\
Sex & $54.81 \pm 10.2$ & \\
Male & & \\
Female & $54.54 \%$ & $53.52 \%$ \\
Ethnicity & $45.46 \%$ & $46.48 \%$ \\
Arab & & \\
Berber & $88 \%$ & $86 \%$ \\
\hline
\end{tabular}

TABLE 3: Routine pathology data of our ACS patients.

\begin{tabular}{lc}
\hline Parameters & SCA patients \\
\hline Total cholesterol $(\mathrm{g} / \mathrm{L})$ & $1.88 \pm 0.73$ \\
HDL $(\mathrm{g} / \mathrm{L})$ & $1.24 \pm 0.9$ \\
LDL $(\mathrm{g} / \mathrm{L})$ & $1.24 \pm 0.64$ \\
Triglycerides TG $(\mathrm{g} / \mathrm{L})$ & $1.53 \pm 1.00$ \\
Glucose $(\mathrm{g} / \mathrm{L})$ & $1.43 \pm 0.8$ \\
Creatinine $(\mathrm{mg} / \mathrm{L})$ & $9.51 \pm 2.46$ \\
Fibrinogen & $3.65 \pm 1.06$ \\
HB $(\mathrm{g} / \mathrm{dL})$ & $13.99 \pm 2.63$ \\
GB $\left(\mathrm{elts} / \mathrm{mm}^{3}\right)$ & $12958.6 \pm 24041.3$ \\
Pq $\left(\mathrm{elts} / \mathrm{mm}^{3}\right)$ & $237151.7 \pm 102412$ \\
$\mathrm{BMI}\left(\mathrm{Kg} / \mathrm{m}^{2}\right)$ & $26.72 \pm 4.17$ \\
$\mathrm{IPP}$ & \\
$(+)$ & $79.6 \%$ \\
$(-)$ & $20.4 \%$ \\
\hline
\end{tabular}

antecedent among SCA patients; no association was detected with the other risk factors (Table 5).

Table 6 shows the distribution of patients ACS type (ST $(+)$ and ST (-)) according to i-T744C P2Y12 genotypic profiles: $62.75 \%$ of the wild-type and $76.48 \%$ of the heterozygous profiles were SCA ST $(-)$, when the majority of the mutated profile was SCA ST $(+)(66.7 \%)$. Mutant allele was more frequent among SCA ST (+) than SCA ST (-) patients $(39 \%$ versus $19.8 \%$, resp.); the wild-type allele was more frequent in SCA ST $(-)$ group than SCA ST $(+)$ one $(80.2 \%$ versus $61 \%$, resp.).

Distribution of resistant and nonresistant patients according to i-T744C P2Y12 genotypes is reported in Table 7: $69.45 \%$ of nonresistant patients are wild-type for this polymorphism; $19.45 \%$ are heterozygous; and $11.1 \%$ are homozygous for the mutation; in the resistant group, $60 \%$ are wild-type, $20 \%$ are heterozygous, and $20 \%$ are homozygous
TABLE 4: Baseline characteristics of our SCA patients versus VerifyNow test results.

\begin{tabular}{|c|c|c|c|}
\hline & Nonresistant $\%$ & Resistant $\%$ & $P$ value \\
\hline Age & $56.9 \pm 8.48$ & $62 \pm 8.02$ & 0.9 \\
\hline Sex & & & 0.41 \\
\hline Male & $58.3 \%$ & $20 \%$ & \\
\hline Female & $41.7 \%$ & $80 \%$ & \\
\hline SCA type & & & 0.2 \\
\hline$S T(+)$ & $36 \%$ & $60 \%$ & \\
\hline$S T(-)$ & $64 \%$ & $40 \%$ & \\
\hline Familial ACD & & & 0.8 \\
\hline Presence & $2.8 \%$ & $0 \%$ & \\
\hline Absence & $97.2 \%$ & $100 \%$ & \\
\hline Personal ACD & & & 0.3 \\
\hline Presence & $41.7 \%$ & $20 \%$ & \\
\hline Absence & $58.3 \%$ & $80 \%$ & \\
\hline Diabetes & & & 0.6 \\
\hline Presence & $40.3 \%$ & $40 \%$ & \\
\hline Absence & $59.7 \%$ & $60 \%$ & \\
\hline HTA & & & 0.46 \\
\hline Presence & $47.2 \%$ & $60 \%$ & \\
\hline Absence & $52.8 \%$ & $40 \%$ & \\
\hline Dyslipidemia & & & 0.22 \\
\hline Presence & $16.7 \%$ & $40 \%$ & \\
\hline Absence & $83.3 \%$ & $60 \%$ & \\
\hline Smoking & & & 0.6 \\
\hline Presence & $40.3 \%$ & $40 \%$ & \\
\hline Absence & $59.7 \%$ & $60 \%$ & \\
\hline Creatinine $(m g / L)$ & $11.6 \pm 10.87$ & $15 \pm 4.34$ & $0.01^{*}$ \\
\hline Fibrinogen & $3.57 \pm 1.06$ & $5.03 \pm 1.14$ & $0.04^{*}$ \\
\hline$P q$ & $242333 \pm 102412$ & $159427 \pm 79609$ & $0.04^{*}$ \\
\hline$I P P$ & & & $0.03^{*}$ \\
\hline Used & $50.38 \%$ & $60 \%$ & \\
\hline Nonused & $49.62 \%$ & $40 \%$ & \\
\hline
\end{tabular}

*Statistically significant.

mutant. The mutant allele is more frequent among resistant than nonresistant patients (30\% and $20.8 \%$, resp.).

Allelic and genotypic frequencies among cases and controls are reported in Table 8: genotypic frequencies were $66.23 \%$ TT, $20.07 \%$ TC, and $11.7 \%$ CC among cases versus $68.32 \% \mathrm{TT}, 24.75 \% \mathrm{TC}$, and $6.93 \% \mathrm{CC}$ among healthy controls. Allelic frequencies were $77.27 \% \mathrm{~T}$ and $22.73 \% \mathrm{C}$ among cases versus $80.69 \% \mathrm{~T}$ and $19.31 \% \mathrm{C}$ among controls. A statistically significant association was found with both TC and CC genotypes $(\mathrm{OR}[95 \% \mathrm{CI}]=0.92[0.45-1.87], P=0.0048$ 
TABLE 5: i-T744C P2Y12 rs2046934 genotypes distribution versus risk factors.

\begin{tabular}{|c|c|c|c|c|}
\hline \multirow{2}{*}{ Risk factor } & \multicolumn{3}{|c|}{ SCA patients } & \multirow{2}{*}{$P$ value $(<0.05)$} \\
\hline & Wild-type $\%$ & Heterozygous\% & Mutant $\%$ & \\
\hline Familial ACD & & & & $0.014^{*}$ \\
\hline Presence & 0 & 100 & 0 & \\
\hline Absence & 71.4 & 17.2 & 11.4 & \\
\hline Personal ACD & & & & 0.6 \\
\hline Presence & 75 & 17.9 & 7.1 & \\
\hline Absence & 65.9 & 20.5 & 13.6 & \\
\hline HTA & & & & 0.8 \\
\hline Presence & 71.4 & 17.2 & 11.4 & \\
\hline Absence & 67.6 & 21.6 & 10.8 & \\
\hline Smoking & & & & 0.51 \\
\hline Presence & 70 & 23.3 & 6.7 & \\
\hline Absence & 69 & 16.7 & 14.3 & \\
\hline Diabetes & & & & 0.71 \\
\hline Presence & 65.5 & 24.2 & 10.3 & \\
\hline Absence & 72.1 & 16.3 & 11.6 & \\
\hline Dyslipidemia & & & & 0.8 \\
\hline Presence & 71.4 & 21.4 & 7.2 & \\
\hline Absence & 69 & 19 & 12 & \\
\hline
\end{tabular}

${ }^{*}$ Statistically significant.

TABLE 6: i-T744C P2Y12 rs2046934 genotypes distribution VS ACS subgroups.

\begin{tabular}{lccccc}
\hline & \multicolumn{3}{c}{ SCA patients } & Wild-type allele & Mutant allele \\
& TT\% & TC\% & CC\% & & value $(<0.05)$ \\
\hline ST $(+)$ & 37.25 & 23.52 & 66.7 & $61 \%$ & $39 \%$ \\
ST $(-)$ & 62.75 & 76.48 & 33.3 & 80.2 & $19.8 \%$ \\
\hline
\end{tabular}

TABLE 7: i-T744C P2Y12 rs2046934 genotypes distribution versus VerifyNow test results.

\begin{tabular}{lccccc}
\hline & & SCA patients & Wild-type allele\% & Mutant allele\% & $P$ value \\
& TT\% & TC\% & CC\% & 79.2 & 20.8 \\
Nonresistant & 69.45 & 19.45 & 11.1 & 70 & 30 \\
Resistant & 60 & 20 & 20 & & 0.45 \\
\hline
\end{tabular}

TABLE 8: Allelic and genotypic frequencies of i-T744C P2Y12 rs2046934 polymorphism among cases and controls.

\begin{tabular}{|c|c|c|c|c|c|}
\hline & Genotypes/alleles & Cases (\%) & Controls (\%) & OR (95\% CI) & $P$ value \\
\hline \multirow{9}{*}{ i-T744C P2Y12 (rs2046934) } & $\mathrm{TT}$ & 66.23 & 68.32 & 1 & \\
\hline & TC & 22.07 & 24.75 & $0.92[0.45-1.87]$ & $0.0048^{*}$ \\
\hline & $\mathrm{CC}$ & 11.7 & 6.93 & $1.74[1.66-5.00]$ & $0.03^{*}$ \\
\hline & $\mathrm{TT}+\mathrm{TC}^{(\mathrm{b})}$ & 88.3 & 93.07 & 1 & \\
\hline & CC & 11.7 & 6.93 & $1.78[1.58-5.05]$ & $0.01^{*}$ \\
\hline & $\mathrm{TT}^{(\mathrm{c})}$ & 66.23 & 68.32 & 1 & \\
\hline & $\mathrm{TC}+\mathrm{CC}$ & 33.77 & 31.68 & $1.1[1.7-2.05]$ & 0.15 \\
\hline & $\mathrm{T}^{(\mathrm{d})}$ & 77.27 & 80.69 & 1 & \\
\hline & $\mathrm{C}$ & 22.73 & 19.31 & $1.23[0.74-2.03]$ & $<0.001^{*}$ \\
\hline
\end{tabular}

${ }^{*}$ Statistically significant.

${ }^{\mathrm{b}}$ Recessive model.

${ }^{\mathrm{c}}$ Dominant model.

${ }^{\mathrm{d}}$ Additive model. 
and OR $[95 \% \mathrm{CI}]=1.74[1.66-5.00], P=0.03$, resp.). There was a positive correlation with the recessive and additive transmission models, but not the dominant one (OR [95\% $\mathrm{CI}]=1.78[1.58-5.05], P=0.01$ and OR $[95 \% \mathrm{CI}]=1.23[0.74-$ 2.03], $P<0.001$, resp.), increasing thus the association of this polymorphism with the pathology.

\section{Discussion}

Clopidogrel is a second-generation thienopyridine, having better efficacy of ticlopidine that represents the first-generation; it has better tolerability profiles and is currently the antiplatelet treatment of choice for prevention of thrombosis events $[24,25]$. An interindividual variation in platelet response to Clopidogrel has been widely reported; it may be explained by several factors, including genetics [6]. Many Single Nucleotide Polymorphisms (SNPs) of the P2Y12 receptor gene were described to be in association with this interindividual variability in ADP-induced platelet aggregation [2628]. i-T744C polymorphism has been associated with enhanced platelet aggregation, suggesting its potential effect on modulating Clopidogrel response $[29,30]$.

Our study is the first to determine the frequency of iT744C P2Y12 polymorphism among Moroccan ACS patients and healthy subjects and to evaluate the correlation between Clopidogrel resistance and genetic testing represented by iT744C P2Y12 polymorphism, among a sample of Moroccan ACS patients.

In our study sample, there was a predominance of male in both cases and controls groups (54.54\% and 53.52\%, resp.); the average age was 57.33 and 32 , respectively, among cases and controls (Table 2). This was in agreement with what Zoheir et al. found in their study about P2Y12 receptor gene polymorphism and antiplatelet effect of Clopidogrel in patients with coronary artery disease after coronary stenting [26].

$79.6 \%$ of our patients were under PPI, when $20.4 \%$ were not (Table 3). PPI use showed a statistically significant association when being correlated to patients groups (resistant and nonresistant patients), divided based on their platelet function test results $(P=0.03)$ (Table 4$)$. Proton-pump inhibitors (PPI) are known to potentially affect the Clopidogrel platelet inhibition relationship [30]; also creatinine level, fibrinogen, and $\mathrm{Pq}$ numerisation showed statistically significant association $(P=0.01 ; 0.04$; and 0.04 , resp.) (Table 4$)$.

Concerning resistant and nonresistant groups of patients, our results were in agreement with Nordeen et al's study: they found the same range of age, with the majority of resistant group being female, compared to nonresistant one [30]. Several studies have suggested that women do not accrue equal therapeutic benefit of antithrombotic therapy [31, 32]. Although multiple contributing factors have been described (differences in vessel wall biology between men and women; the direct influence of sex hormones (oestrogens, progesterone, or androgens) on platelets and their indirect effect on the vasculature), the physiological mechanism behind this gender disparity remains unclear [33].

A statistical comparison was held between distribution of i-T744C polymorphism among ACS patients and traditional risk factors; we found significant association only with familial antecedent factor $(P=0.014$; Table 5). Correlation between this polymorphism and ACS subgroups (ST+ and $\mathrm{ST}-$ ) showed that the majority of wild-type and heterozygous profiles were SCA ST (-), when the majority of the mutated profiles were SCA ST (+) (Table 6). Mutant allele was more frequent among SCA ST (+) patients, when wild-type allele was more present in SCA ST (-) group. Distribution of resistant and nonresistant patients according to i-T744C P2Y12 genotypes showed that $69.45 \%$ of nonresistant patients had the wild-type profile; $19.45 \%$ were heterozygous; and $11.1 \%$ were homozygous mutant; in the resistant group, $60 \%$ were wild-type, $20 \%$ heterozygous, and $20 \%$ homozygous mutant. The mutant allele was more frequent among resistant than nonresistant patients (30\% and $20.8 \%$, resp.). Zoheir et al. [26] found a higher expression of $\mathrm{C}$ allele (heterozygous CT and homozygous CC) among nonresponder ACS patients $(P<0.001)$. Fontana et al. [29] also found similar results suggesting that the $\mathrm{H} 2$ haplotype of the $\mathrm{P} 2 \mathrm{Y} 12$ gene is associated with increased platelet function in nonmedicated healthy volunteers. On the contrary, the results of Cuisset et al. [18] show no influence of i-T744C P2Y12 polymorphism on Clopidogrel response. Platelet function studies performed by Lev et al. [12] in the same context did not show any modulating effect of this genetic polymorphism on individual responsiveness to Clopidogrel. Furthermore, Hetherington et al. [34] reported no significant effect of i-T744C P2Y12 SNP on platelet response to ADP among subjects without cardiovascular disease history.

In our study, we tried also to investigate whether the mutant allele C of i-T744C P2Y12 polymorphism has an effect on ACS occurrence. Our results revealed that the mutant allele $\mathrm{C}$ was more frequent among cases than controls $(22.73 \%$ versus $19.31 \%$, resp.). A statistically significant association was found with both TC and CC genotypes (OR [95\% CI] $=0.92$ [0.45-1.87], $P=0.0048$ and OR [95\% CI] $=1.74$ [1.66-5.00], $P=0.03$, resp.). There was a positive correlation between the recessive and additive transmission models and ACS risk, but not the dominant one (OR $[95 \% \mathrm{CI}]=1.78$ [1.58-5.05], $P=$ 0.01 and $\mathrm{OR}[95 \% \mathrm{CI}]=1.23[0.74-2.03], P<0.001$, resp.), increasing thus the association of this polymorphism with the risk of pathology development. Our findings matches those of Zoheir et al. [26]; they reported that this polymorphism was positively correlated to increased risk of disease development (OR $=14.8,95 \%, C I=1.8-121.1$, and $P=0.002)$. Similar findings were published by Cavallari et al. [35], who found that nonsmokers carrying the minor haplotype $\mathrm{H} 2$ of the gene were highly associated with significant CAD (OR $=1.83,95 \%$ $\mathrm{CI}=1.17-2.87$, and $P=0.007)$. On the other side, findings of Schettert et al. [36] did not provide evidence for a strong association between $\mathrm{H} 1 / \mathrm{H} 1$ and $\mathrm{H} 1 / \mathrm{H} 2$ haplotypes and any increased risk of cardiovascular events in a population with CAD.

\section{Conclusion}

To the best of our knowledge, our study is the first in Morocco to assess whether or not Clopidogrel response may be modulated by i-T744C P2Y12 polymorphism in a sample 
of Moroccan ACS patients. We tried also to determine the frequency of this polymorphism among Moroccan ACS and healthy subjects. Our findings suggest that the wild-type and heterozygous genotypic profiles were more frequent among ACS ST (-) patients, when the homozygous mutant genotype was more frequent among ACS ST (+). The mutant allele C was more frequent among ACS ST (+) than ACS ST (-) patients, when the wild-type allele was more represented in the ACS ST (-) group. The C allele frequency was higher among resistant than nonresistant patients. Comparison of ACS patients and healthy controls shows higher frequency of $\mathrm{C}$ allele among cases than controls; there was a statistically significant association of the recessive and additive transmission models with the ACS development risk, increasing thus the association of this polymorphism with the pathology. Further studies including larger sample sizes and exploring interactions between this polymorphism and others are still be needed and may provide useful information to better understand the mechanism of Clopidogrel interindividual resistance and also the risk of ACS occurrence in the option to improve the biomedical context.

\section{Competing Interests}

The authors declare that they have no financial or nonfinancial competing interests.

\section{References}

[1] G. H. Guyatt, D. J. Cook, R. Jaeschke, S. G. Pauker, and H. J. Schünemann, "Grades of recommendation for antithrombotic agents: American College of Chest Physicians evidence-based clinical practice guidelines (8th edition)," Chest, vol. 133, no. 6, 2008.

[2] S. B. King III, S. C. Smith Jr., J. W. Hirshfeld Jr. et al., "2007 focused update of the ACC/AHA/SCAI 2005 Guideline Update for Percutaneous Coronary Intervention: a report of the American College of Cardiology/American Heart Association Task Force on Practice Guidelines: 2007 writing group to review new evidence and update the ACC/AHA/SCAI 2005 Guideline Update for Percutaneous Coronary Intervention, Writing on behalf of the 2005 Writing Committee," Circulation, vol. 117, no. 2, pp. 261-295, 2007.

[3] F. Marín, R. González-Conejero, P. Capranzano, T. A. Bass, V. Roldán, and D. J. Angiolillo, "Pharmacogenetics in cardiovascular antithrombotic therapy," Journal of the American College of Cardiology, vol. 54, no. 12, pp. 1041-1057, 2009.

[4] D. J. Angiolillo, A. Fernandez-Ortiz, E. Bernardo et al., "Variability in individual responsiveness to clopidogrel: clinical implications, management, and future perspectives," Journal of the American College of Cardiology, vol. 49, no. 14, pp. 1505-1516, 2007.

[5] T. H. Wang, D. L. Bhatt, and E. J. Topol, "Aspirin and clopidogrel resistance: an emerging clinical entity," European Heart Journal, vol. 27, no. 6, pp. 647-654, 2006.

[6] W. E. Evans and H. L. McLeod, "Pharmacogenomics-drug disposition, drug targets, and side effects," New England Journal of Medicine, vol. 348, no. 6, pp. 538-549, 2003.
[7] D. Taubert, N. von Beckerath, G. Grimberg et al., "Impact of Pglycoprotein on clopidogrel absorption," Clinical Pharmacology and Therapeutics, vol. 80, no. 5, pp. 486-501, 2006.

[8] D. J. Angiolillo, A. Fernandez-Ortiz, E. Bernardo et al., "Contribution of gene sequence variations of the hepatic cytochrome P450 3A4 enzyme to variability in individual responsiveness to clopidogrel," Arteriosclerosis, Thrombosis, and Vascular Biology, vol. 26, no. 8, pp. 1895-1900, 2006.

[9] J.-W. Suh, B.-K. Koo, S.-Y. Zhang et al., "Increased risk of atherothrombotic events associated with cytochrome P450 3A5 polymorphism in patients taking clopidogrel," CMAJ, vol. 174, no. 12, pp. 1715-1722, 2006.

[10] J.-S. Hulot, A. Bura, E. Villard et al., "Cytochrome P450 2C19 loss-of-function polymorphism is a major determinant of clopidogrel responsiveness in healthy subjects," Blood, vol. 108, no. 7, pp. 2244-2247, 2006.

[11] N. Von Beckerath, O. Von Beckerath, W. Koch, M. Eichinger, A. Schömig, and A. Kastrati, "P2Y12 gene H2 haplotype is not associated with increased adenosine diphosphate-induced platelet aggregation after initiation of clopidogrel therapy with a high loading dose," Blood Coagulation and Fibrinolysis, vol. 16, no. 3, pp. 199-204, 2005.

[12] E. I. Lev, R. T. Patel, S. Guthikonda, D. Lopez, P. F. Bray, and N. S. Kleiman, "Genetic polymorphisms of the platelet receptors $\mathrm{P}_{2} \mathrm{Y}_{12}, \mathrm{P}_{2} \mathrm{Y}_{1}$ and GP IIIa and response to aspirin and clopidogrel," Thrombosis Research, vol. 119, no. 3, pp. 355-360, 2007.

[13] J. Dropinski, J. Musial, B. Jakiela, W. Wegrzyn, M. Sanak, and A. Szczeklik, "Anti-thrombotic action of clopidogrel and $\mathrm{PI}^{A 1 / A 2}$ polymorphism of $\beta_{3}$ integrin in patients with coronary artery disease not being treated with aspirin," Thrombosis and Haemostasis, vol. 94, no. 6, pp. 1300-1305, 2005.

[14] H. H. Hassani Idrissi, W. Hmimech, N. El Khorb, H. Akoudad, R. Habbal, and S. Nadifi, "Association of the C3435T MultiDrug Resistance gene-1 (MDR-1) polymorphism with Clopidogrel resistance among Moroccan Acute Coronary Syndromes (ACS) patients," Journal of Thrombosis and Circulation, vol. 2, article 115, 2016.

[15] M. V. Holmes, P. Perel, T. Shah, A. D. Hingorani, and J. P. Casas, "CYP2C19 genotype, clopidogrel metabolism, platelet function, and cardiovascular events a systematic review and meta-analysis," The Journal of the American Medical Association, vol. 306, no. 24, 2011.

[16] L. A. Malek, B. Kisiel, M. Spiewak et al., "Coexisting polymorphisms of $\mathrm{P} 2 \mathrm{Y} 12$ and $\mathrm{CYP} 2 \mathrm{C} 19$ genes as a risk factor for persistent platelet activation with clopidogrel," Circulation Journal, vol. 72, no. 7, pp. 1165-1169, 2008.

[17] D. J. Angiolillo, A. Fernandez-Ortiz, E. Bernardo et al., "Lack of association between the $\mathrm{P} 2 \mathrm{Y} 12$ receptor gene polymorphism and platelet response to clopidogrel in patients with coronary artery disease," Thrombosis Research, vol. 116, no. 6, pp. 491-497, 2005.

[18] T. Cuisset, C. Frere, J. Quilici et al., "Role of the T744C polymorphism of the P2Y12 gene on platelet response to a 600 -mg loading dose of clopidogrel in 597 patients with non-ST-segment elevation acute coronary syndrome," Thrombosis Research, vol. 120, no. 6, pp. 893-899, 2007.

[19] G. Hollopeter, H.-M. Jantzen, D. Vincent et al., "Identification of the platelet ADP receptor targeted by antithrombotic drugs," Nature, vol. 409, no. 6817, pp. 202-207, 2001.

[20] A. Malinin, A. Pokov, M. Spergling et al., "Monitoring platelet inhibition after clopidogrel with the VerifyNow-P2Y12 ${ }^{\circledR}$ rapid 
analyzer: the VERIfy Thrombosis risk ASsessment (VERITAS) study," Thrombosis Research, vol. 119, no. 3, pp. 277-284, 2007.

[21] S. Prabhakaran, K. R. Wells, V. H. Lee, C. A. Flaherty, and D. K. Lopes, "Prevalence and risk factors for aspirin and clopidogrel resistance in cerebrovascular stenting," American Journal of Neuroradiology, vol. 29, no. 2, pp. 281-285, 2008.

[22] A. Y. Gasparyan, "Aspirin and clopidogrel resistance: methodological challenges and opportunities," Vascular Health and Risk Management, vol. 6, no. 1, pp. 109-112, 2010.

[23] S. A. Miller, D. D. Dykes, and H. F. Polesky, "A simple salting out procedure for extracting DNA from human nucleated cells," Nucleic Acids Research, vol. 16, no. 3, article 1215, 1988.

[24] S. C. Smith Jr., T. E. Feldman, J. W. Hirshfeld Jr. et al., "ACC/AHA/SCAI 2005 guideline update for Percutaneous Coronary Intervention: a report of the American College of Cardiology/American Heart Association Task Force on practice guidelines (ACC/AHA/SCAI Writing Committee to update the 2001 guidelines for Percutaneous Coronary Intervention)," Journal of the American College of Cardiology, vol. 47, no. 1, pp. e1-e121, 2006.

[25] H. J. Bouman, J. W. van Werkum, G. Rudež et al., "The relevance of P2Y12-receptor gene variation for the outcome of clopidogrel-treated patients undergoing elective coronary stent implantation: a clinical follow-up," Thrombosis and Haemostasis, vol. 107, no. 1, pp. 189-191, 2012.

[26] N. Zoheir, S. A. Elhamid, N. Abulata, M. E. Sobky, D. Khafagy, and A. Mostafa, "P2Y12 receptor gene polymorphism and antiplatelet effect of clopidogrel in patients with coronary artery disease after coronary stenting," Blood Coagulation and Fibrinolysis, vol. 24, no. 5, pp. 525-531, 2013.

[27] T. Simon, C. Verstuyft, M. Mary-Krause et al., "Genetic determinants of response to clopidogrel and cardiovascular events," New England Journal of Medicine, vol. 360, no. 4, pp. 363-375, 2009.

[28] O. V. Sirotkina, A. M. Zabotina, O. A. Berkovich, E. A. Bazhenova, T. V. Vavilova, and A. L. Shvartsman, "Genetic variants of platelet ADP receptor P2Y12 associated with changed platelet functional activity and development of cardiovascular diseases," Genetika, vol. 45, no. 2, pp. 247-253, 2009.

[29] P. Fontana, A. Dupont, S. Gandrille et al., "Adenosine diphosphate-induced platelet aggregation is associated with P2Y12 gene sequence variations in healthy subjects," Circulation, vol. 108, no. 8, pp. 989-995, 2003.

[30] J. D. Nordeen, A. V. Patel, and R. M. Darracott, "Clopidogrel resistance by $\mathrm{P} 2 \mathrm{Y} 12$ platelet function testing in patients undergoing neuroendovascular procedures: incidence of ischemic and hemorrhagic complications," Journal of Vascular and Interventional Neurology, vol. 6, no. 1, pp. 26-34, 2013.

[31] J. S. Berger, M. C. Roncaglioni, F. Avanzini, I. Pangrazzi, G. Tognoni, and D. L. Brown, "Aspirin for the primary prevention of cardiovascular events in women and men: a sex-specific meta-analysis of randomized controlled trials," Journal of the American Medical Association, vol. 295, no. 3, pp. 306-316, 2006.

[32] E. Boersma, R. A. Harrington, D. J. Moliterno et al., "Platelet glycoprotein IIb/IIIa inhibitors in acute coronary syndromes: a meta-analysis of all major randomised clinical trials," The Lancet, vol. 359, no. 9302, pp. 189-198, 2002.

[33] N. Jochmann, K. Stangl, E. Garbe, G. Baumann, and V. Stangl, "Female-specific aspects in the pharmacotherapy of chronic cardiovascular diseases," European Heart Journal, vol. 26, no. 16, pp. 1585-1595, 2005.
[34] S. L. Hetherington, R. K. Singh, D. Lodwick, J. R. Thompson, A. H. Goodall, and N. J. Samani, "Dimorphism in the P2Y1 ADP receptor gene is associated with increased platelet activation response to ADP," Arteriosclerosis, Thrombosis, and Vascular Biology, vol. 25, no. 1, pp. 252-257, 2005.

[35] U. Cavallari, E. Trabetti, G. Malerba et al., "Gene sequence variations of the platelet $\mathrm{P} 2 \mathrm{Y} 12$ receptor are associated with coronary artery disease," BMC Medical Genetics, vol. 8, article no. 59, 2007.

[36] I. T. Schettert, A. C. Pereira, N. H. Lopes, W. A. Hueb, and J. E. Krieger, "Association between platelet P2Y12 haplotype and risk of cardiovascular events in chronic coronary disease," Thrombosis Research, vol. 118, no. 6, pp. 679-683, 2006. 

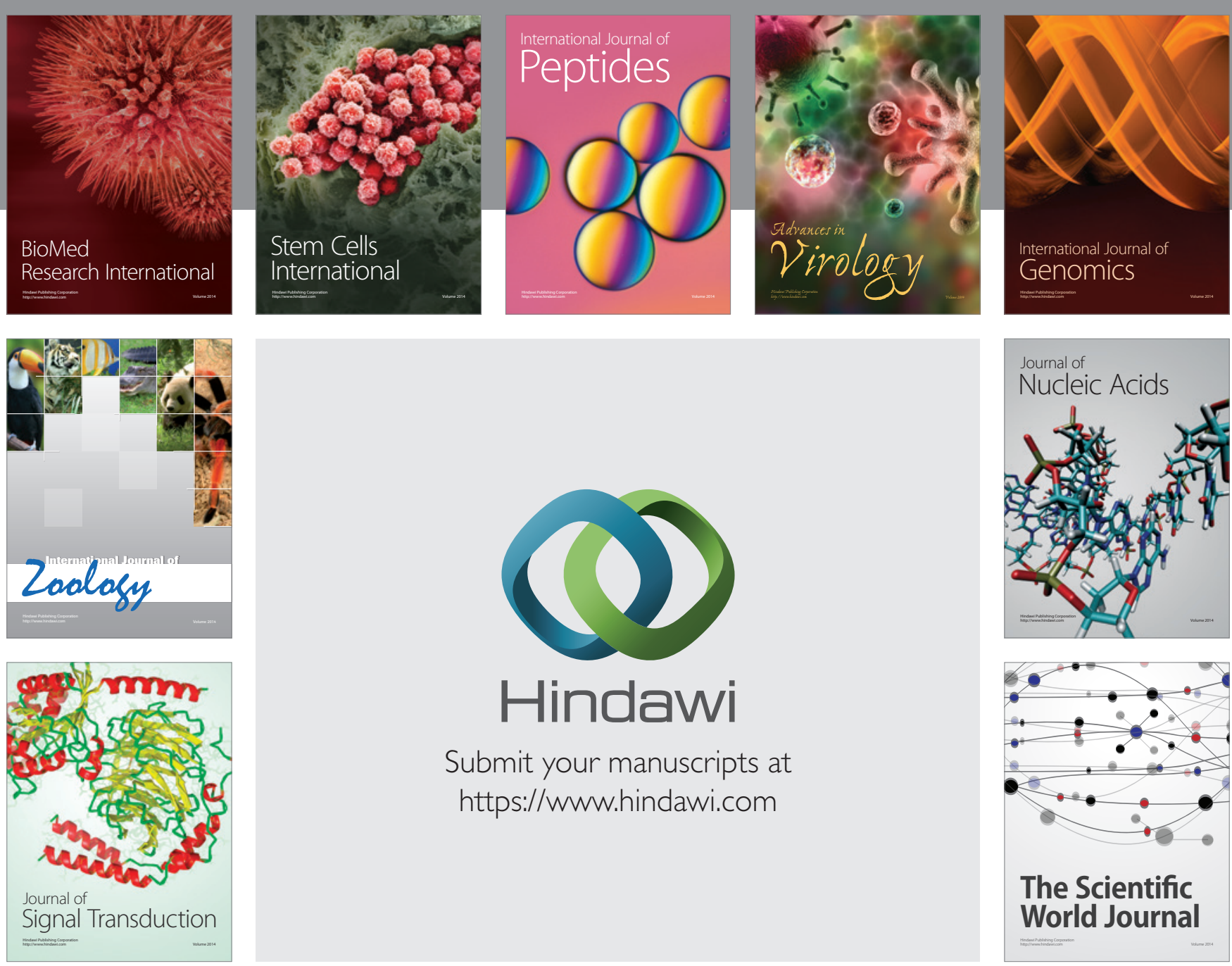

Submit your manuscripts at

https://www.hindawi.com
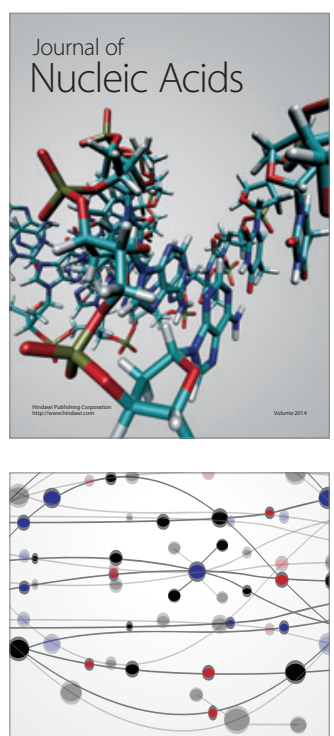

The Scientific World Journal
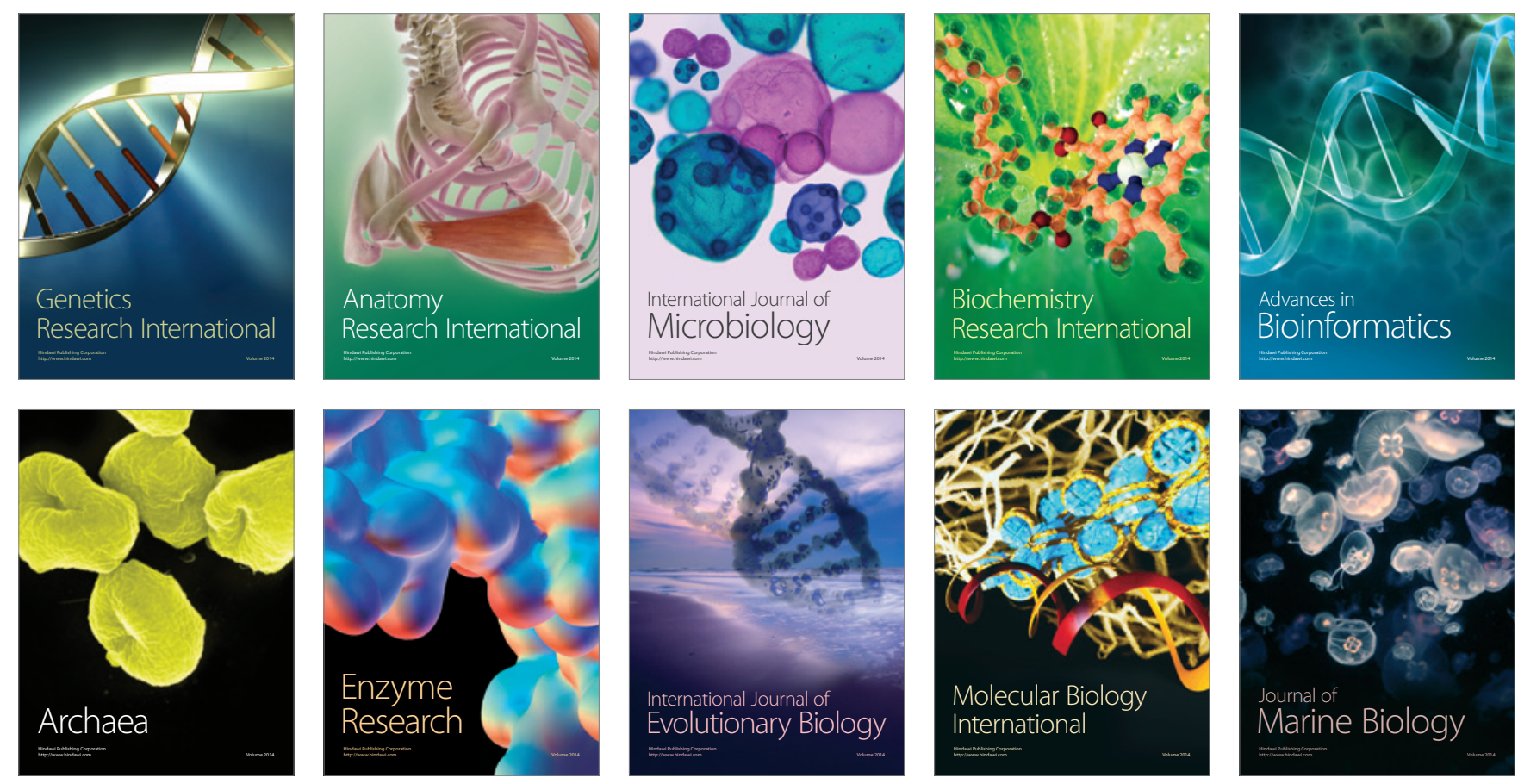